\title{
Surgical repair of left ventricular rupture after the use of tenecteplase in the treatment of acute myocardium infarction
}

\author{
Reparo de rotura de ventrículo esquerdo após uso de tenecteplase no tratamento do infarto agudo do \\ miocárdio
}

Marco Antonio Vieira GUEDES, Carlos Edson Campos CUNHA FILHO, Alexandre Ciappina HUEB, Sérgio Almeida de OLIVEIRA

RBCCV 44205-750

\begin{abstract}
The use of thrombolytic agents in the treatment of acute myocardium infarction represented an important impact in the reduction of overall mortality. But this did not alter the cardiac rupture rate. This complication must be recognized and treated quickly. The authors report on a case of surgical repair of an early left ventricle rupture, after the use of tenecteplase in association with non-fractioned heparin for the treatment of acute myocardium infarction.
\end{abstract}

Descriptors: Myocardial infarction. Thrombolytic therapy, adverse effects. Heart rupture, post infarction.

\section{Resumo}

A utilização do trombolítico no tratamento do infarto agudo do miocárdio apresentou um impacto importante na diminuição da mortalidade geral, porém não alterou a incidência da rotura cardíaca. Esta complicação deve ser reconhecida e tratada rapidamente, necessitando um alto nível de suspeição clínica. Os autores relatam um caso de reparo cirúrgico de rotura precoce de ventrículo esquerdo, após utilização de tenecteplase associado à heparina não fracionada, no tratamento do infarto agudo do miocárdio.

Descritores: Infarto do miocárdio. Terapia trombolítica, efeitos adversos. Ruptura cardíaca pós-infarto.

Work developed in the Instituto do Coração do Hospital das Clínicas, Medical School of the University of São Paulo, São Paulo - SP. 


\section{INTRODUCTION}

Rupture of the left ventricular free wall or ventricular septum is an important complication of acute myocardial infarction (AMI), occurring in from $1 \%$ to $3 \%$ of all patients who suffer from this problem.

Rupture is more frequently diagnosed after death than in live patients. Nearly $20 \%$ of patients who die due to AMI present with heart rupture making this the third highest cause of death after cardiogenic shock and ventricular arrhythmias [1].

In respect to the anatomoclinical findings of autopsies, this complication is observed more frequently in over 60year-old women, with evidence of single arterial disease, victims of their first infarction, suffering from hypertension without ventricular hypertrophy and normally submitted to thrombolytic therapy. The use of thrombolytic therapy in the treatment of AMI, in spite of reducing the overall mortality, seems to accelerate the evolution to heart rupture, without necessarily increasing the incidence of this complication. Reperfusion phenomena seem to favor early heart rupture due to the transformation of ischemic infarction to hemorrhagic infarction [2].

Rupture can occur some hours after of the beginning of symptoms. Precocious and effective thrombolysis decreases the risk of heart rupture, maybe by limiting the extent of myocardial necrosis, thereby avoiding transmural infarction. But, the impact of late thrombolytic therapy in heart rupture remains unknown $[2,3]$.

The aim of this work is to report on a case of surgical repair of precocious left ventricle rupture, after the use of tenecteplase associated with non-fractionated heparin, for the treatment of AMI.

\section{CASEREPORT}

In May 2004 a 62-year-old female diabetics taking oral hypoglycemiant and suffering from hypertension and dyslipidemia presented with an episode of a moderate burning precordial pain during resting. After three days the patient consulted a physician and was diagnosed as having AMI with positive deflection of the ST segment in the anterior wall, evolving to Killip I. The electrocardiogram (ECG) revealed: an inactive area in the anterior and inferior wall, associated with the positive 2$\mathrm{mm}$ deflection of the ST segment in the anterior wall. A transthoracic echocardiogram (ECO) revealed: ejection fraction (EF) of 35\% with important involvement of the left ventricle systolic function due to an apical aneurysm and basal paralysis of the inferior wall. The patient was submitted to a heart catheterism (CAT) which showed three-arterial coronary obstruction: the right coronary artery occluded in the middle $1 / 3$, the anterior interventricular artery occluded in the middle $1 / 3$, the circumflex artery (CxA) with a lesion of $90 \%$ in the middle $1 / 3$, the left marginal arteries with a critical lesion in the proximal $1 / 3$, grade III collateral circulation to the right coronary artery, as well as the inferior apical aneurysm. The patient was submitted to the classical treatment for AMI without primary reperfusion therapy, receiving hospital discharge on the $8^{\text {th }}$ day after hospital admission when an elective coronary artery bypass grafting surgery was scheduled.

After fifteen days the patient presented with a new episode of a strong precordial pain during rest associated with dyspnea arriving at the Emergency Department of the Heart Institute of São Paulo 40 minutes after the start of the symptoms. At admission, the ECG revealed a positive 6-mm deflection of the ST segment in the anterior wall associated with an inactive area in the anterior and inferior wall and another myocardial infarction in the anterior wall was diagnosed with a positive deflection of ST segment. The patient was submitted to thrombolytic therapy 1 hour 40 minutes after the start of the symptoms, using $40 \mathrm{mg}$ tenecteplase (TNK-tPA) via endovenous and 4500 units nonfractionated heparin via endovenous. After thrombolysis, the patient was submitted to another CAT which did not demonstrate any changes when compared to the first coronary pattern.

After 4 hours of thrombosis, the patient evolved with hemodynamic instability, pulmonary congestion, reduced mental awareness, presenting with clinical signs of cardiogenic shock and requiring vasoactive drugs. There was no hemodynamic improvement and the therapeutic option was the installation of an intra-aortic balloon counterpulsation and emergency coronary artery bypass grafting surgery was indicated.

In the trans-operative period, after opening the pericardium, the presence of significant hemopericardium was observed with adherence to the left ventricular anterior wall of the pericardium. Without touching the region, a cardiopulmonary bypass was established and only after aortic clamping, removal of the adherence from the anterior and apical region was initiated.

After removal, the presence of an anterior wall aneurysm with left ventricular rupture and pseudo-aneurysm formation was observed. Figure 1 demonstrates the intraoperative aspect of the lesion. After resection of the pseudo-aneurysm and repair of the edges of the aneurysm, endoaneurysm repair was initiated utilizing a bovine pericardial patch with reinforcement of the ventricular raffia using two strips of Teflon (Figure 2). Myocardial revascularization was performed, utilizing anastomosed saphenous vein graft for the left marginal arteries and to the posterior interventricular right coronary artery. 


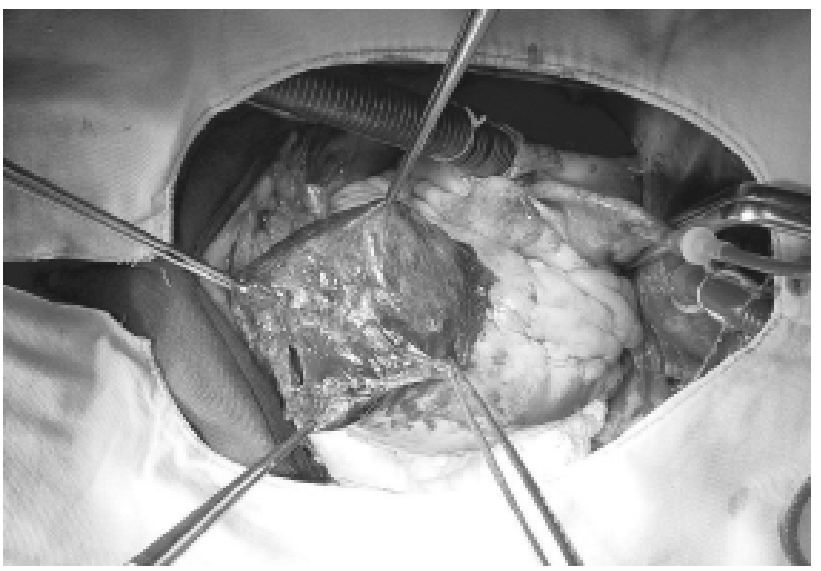

Fig. 1 - Aneurysm in anterior wall of the torn left ventricle

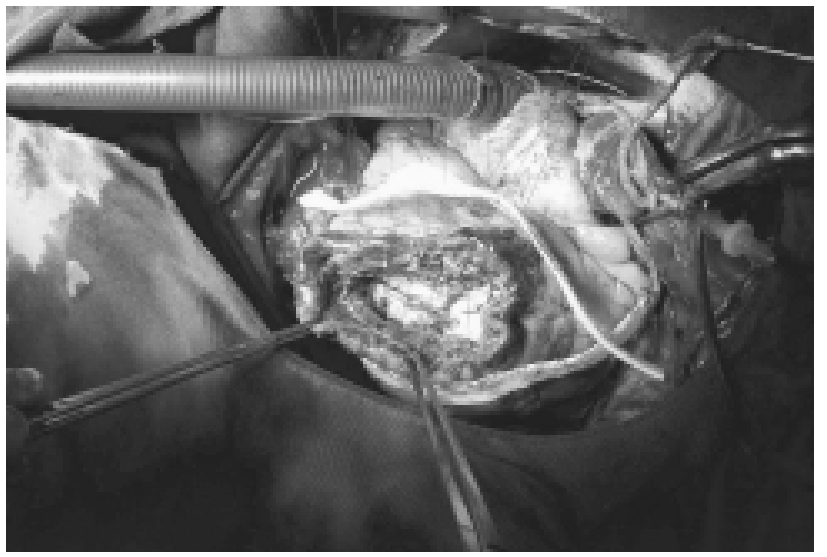

Fig. 2 - Intraoperative aspect of the repair of the left ventricular rupture using the D'or technique. After the left ventricle remodeling with a bovine pericardial patch, the ventricle is closed using individual sutures anchored with two Teflon strips

The removal of the cardiopulmonary bypass was helped by inotropic drugs, an intra-aortic balloon was uneventfully inserted and the patient was moved to the surgical ICU. The patient evolved with progressive hemodynamic improvement, with removal of the intra-aortic balloon performed on the $4^{\text {th }}$ postoperative day. She was released from the ICU on the $6^{\text {th }}$ postoperative day with a CK-MB mass peak at $64.7 \mathrm{ng} / \mathrm{dL}$.

The patient received hospital discharge on the $17^{\text {th }}$ postoperative day taking acetylsalicylic acid $200 \mathrm{mg} / \mathrm{day}$, enalapryl $200 \mathrm{mg} /$ day, carvedilol $100 \mathrm{mg} /$ day, digoxin $0.25 \mathrm{mg} /$ day, sinvastatin $20 \mathrm{mg} /$ day and glybenclamid $2.5 \mathrm{mg} /$ day. An ECHO at hospital discharge showed the Ejection Fraction (EF) at 39\% with apical akinesia and an aneurysm of the basal region of the inferior septum and of the inferior-posterior wall.

\section{COMMENTS}

Heart rupture after AMI occurs when the transmural pressure is greater than the tensile force of the heart conjunctive tissue. This occurs, generally, at the weakest site of the ventricular wall, located in the non-complacent zone of the infarcted area. The use of thrombolytic therapy in the treatment of AMI has an important impact in reducing the overall mortality, but the rupture rate remains unaltered [4].

Successful thrombolysis performed up to 6 hours from the start of the symptoms, reduces the risk of rupture, maybe by limiting the extent of the myocardial necrosis, reducing the probability of transmural infarction occurring. After this period, the impact of thrombolytic therapy remains uncertain. The LATE (Late Assessment of Thrombolytic Efficacy) Study was not able to conclusively demonstrate that late use of thrombolysis increases the rupture rate, despite the fact that rupture occurs earlier [2,4]. The reperfusion phenomenon seems to favor early heart rupture due to the transformation of the ischemic infarction into hemorrhagic infarction [4].

Tenecteplase (TNK-tPA) is a variant of the native tissue plasminogen activator (tPA), produced by means of recombinant DNA technology. The substitution of some amino acids grants a half life to the TNK-tPA greater than alteplase (18 min and $4 \mathrm{~min}$, respectively) greater specificity to fibrin (14 times) and more resistance to PAI-I (80 times) and can be utilized as a unique bolus dose. The TNK-tPA presents the same efficacy as alteplase in a 90-minute administration regimen, without increasing the rate of intracranial bleeding, but reducing non-neurological complications and the use of blood derivatives. Ventricular rupture after the utilization of this thrombolytic therapy is a rare complication, occurring in only $3.2 \%$ of the 6095 patients involved in the ASSENT-3 study. This study evaluated the efficacy and safety of the tenecteplase in association with enoxaparin, abciximab or non-fractioned heparin [5].

The principles of the surgical repair are: to interrupt bleeding, to anchor the repair in viable tissues and to maintain the ventricular geometry. Several techniques can be utilized to this end. Early recognition of the complication and rapid intervention are important for therapeutic success. The use of the intra-aortic balloon reduces the transmural tension and can be an important adjunct therapy in the control of these patients [4,6].

Heart rupture after utilization of the thrombolytic therapy in acute myocardial infarction treatment is a severe complication, which must be recognized and rapidly treated. However, a high level of suspicion is necessary to identify patients who may evolve with hemodynamic instability after the use of thrombolytic therapy. 


\section{BIBLIOGRAPHIC REFERENCES}

1. Reddy SG, Roberts WC. Frequency of rupture of the left ventricular free wall or ventricular septum among necropsy cases of fatal acute myocardial myocardial infarction since introduction of coronary care units. Am J Cardiol. 1989;63(13):906-11.

2. Becker RC, Charlesworth A, Wilcox RG, Hampton J, Skene A, Gore JM et al. Cardiac rupture associated with thrombolytic therapy: impact of time to treatment in the Late Assessment of Thrombolytic Efficacy (LATE) study. J Am Coll Cardiol. 1995;25(5):1063-8.

3. Honan MB, Harrell Jr. FE, Reimer KA, Califf RM, Mark DB, Pryor DB et al. Cardiac rupture, mortality and timing of thrombolytic therapy: a meta-analysis. J Am Coll Cardiol. 1990;16(2):359-67.
4. Park WM, Connery CP, Hochman JS, Tilson MD, Anagnostopoulos CE. Successful repair of myocardial free wall rupture after thrombolytic therapy for acute infarction. Ann Thorac Surg. 2000;70(4):1345-9.

5. Assessment of the Safety and Efficacy of a New Thrombolytic Regimen (ASSENT-3) Investigators. Efficacy and safety of tenecteplase in combination with enoxaparin, abciximab, or unfractionated heparin: the ASSENT-3 randomised trial in acute myocardial infarction. Lancet. 2001;358(9282):605-13.

6. Kirklin JW, Barratt-Boyes BG. Aortic valve disease. In: Kirklin JW, Barratt-Boyes BG, editors. Cardiac surgery. New York:Wiley;2003. p.437-55. 